\title{
A. CUNQUEIRO Y CERVANTES: JUEGOS DE ERUDICIÓN .
}

\section{INTRODUCCIÓN}

La sombra de Cervantes se ha hecho tan evidente en los diversos sistemas literarios que los críticos apenas se molestan en identificar y analizar su presencia en los textos literarios más recientes, y cuando se aventuran en tal empresa reducen sus pesquisas a los niveles más obvios: citas o referencias directas, sin el menor interés por articular las relaciones intertextuales que este diálogo pueda haber generado '. Gonzalo Sobejano, en uno de los más recientes intentos por seguir la pista cervantina en la novela española contemporánea, da un salto cualitativo al identificar algunos de los rasgos del ugesto de Cervantes respecto a la invención narrativa" ${ }^{2}$ que determinados novelistas se han apropiado, fundamentalmente el diálogo ${ }^{3}$. Pero sus indagaciones se reducen a polemizar sobre algunas de las consideraciones que Benet, Goytisolo o Torrente Ballester, entre los más significados, publicaron en torno a la obra y al pensamiento cervantinos; en el último apartado, sin embargo, Sobejano contrasta el «diálogo cervantino y [el] diálogo modernow, preguntándose por kla posible ejemplaridad cervantina en la memoria en forma dialogadaw 4; y cita una serie de «novelas españolas contemporáneas que practican el diálogo dual al servicio de la memorian: Diálogos de la vida y la muerte (J. M. Vaz de Soto), Retahílas y El cuarto de atrás (C. Martín Gaite), Las guerras de nuestros antepasados (M. Delibes),

1 Un modelo de este tipo de crítico es el representado por el artículo de Kessel SCHWARTZ "Cervantes and Contemporary Hispanic Fiction», The Southern Quarterly, XVI, 1, 1977, pp. 39-45.

2 JuAn Benet, «Onda y corpúsculo en el Quijoten, en La moviola de Euripides y otros ensayos. Madrid, Taurus, 1981, p. 81.

3 Gonzalo Sobejano, "Cervantes en la novela española contemporáneaw, La Torre, I, 3/4, 1987, pp. 549-74.

- Sobejano, op. cit., p. 568. 
Luz de la memoria (L. Ortiz), Fragmentos de apocalipsis (Torrente Ballester), y Gramática parda (J. García Hortelano), entre otras.

El inventario, aunque aceptable, está lejos de ser completo, y me imagino que el autor del artículo no pretendía agotar el repertorio de textos narrativos españoles contemporáneos sobre los que planea la sombra cervantina. Hay, sin embargo, autores como Alvaro Cunqueiro que de ninguna forma pueden ser silenciados cuando se trata de seguir la estela cervantina en la producción narrativa española contemporánea. Y esta ausencia es tanto más incomprensible cuanto que Sobejano posee, como indica en el mismo trabajo, una especial sensibilidad hacia un tipo muy cunqueiriano de discurso narrativo:

Por esos primeros años 70 , apenas abarcados en mi apreciación de entonces, se estaba abriendo paso, en un clima de ruptura, un tipo de novela cuyos rasgos determinantes venían a ser, para mi, a fines de 1979 , la memoria en forma preferentemente dialogada, la autocrítica de la escritura, y la fantasía. $Y$ estos tres rasgos se remontan directa $o$ indirectamente al paradigma cervantino, ya no al picaresco s.

Efectivamente, Cervantes había inaugurado una concepción del acto narrativo, y literario en general, en el que los "tres rasgos" identificados por Sobejano desempeñaban una función estructurante. Menos aceptable es la aventurada sugerencia de que habría que esperar a la década de los 70 para detectar los primeros pasos de un modelo narrativo capaz de retomar esta tradición cervantina en la producción narrativa de posguerra.

Como tantos otros aspectos de la producción literaria de A. Cunqueiro, su obra narrativa apenas ha merecido la atención de la crítica; y lógicamente este silencio repercute en los mútiples aspectos que configuran la concepción literaria del escritor gallego, tan próxima a la de Cervantes como demuestra el amplio y variado repertorio de citas, alusiones, comentarios y paráfrasis de su obra en la producción cunqueiriana. Y sin embargo, $\mathrm{R}$. Carballo Calero en su Historia da literatura galega contemporánea (1808-1936) ya observaba, al analizar Cuando el viejo Sinbad vuelva a las islas, que «Sinbad é un Don Quijote, que mesmo ten un Sancho - Sarie unha Dulcinea - Albaw ${ }^{\circ}$ Y un poco más adelante, ratificando el comentario anterior, señalaba otro paralelismo, éste referido a la presencia de la literatura artúrica en ambos autores:

Como cando Cervantes imita a linguaxe dos antigos libros de cabalarías, estamos aquí nos límites antre a entrega a unha tradición e a crítica paródica da mesma; ante a emoción asoballante e a brillante retórica. É que a actitude de Cunqueiro perante o seu asunto é ambigua, e esa ambigüedade constitúi unha fonte de eficacia estética para o lector avisado?

s Sobejano, op. cit., p. 568. Subrayado mío.

- R. Carballo Calero, Historia da literatura galega contemporánea Vigo, Galaxia, 1981, 3.: ed., p. 759.

7 Carballo Calero, op. cit., p. 766. 
Esta segunda anotación sobre la literatura de caballerías, que constata un elemento plenamente reconocido en Cunqueiro, aporta una serie de claves especialmente relevantes para ayudarnos a caminar en el complejo y profuso mundo de la dinámica intertextual cervantina en la obra del escritor mindoniense: en primer lugar, la tensión resultante de la difícil convivencia del respeto a una determinada tradición literaria y la actitud subversiva representada por su lectura paródica; y luego, la ambigüedad que matiza todos y cada uno de los elementos más característicos de la obra cunqueiriana, rasgo que comparte con la producción más significativa de Cervantes.

A estas primeras y esporádicas insinuaciones de Carballo Calero siguieron otras no menos circunstanciales de otros críticos, que tienen el mérito de incidir en la importancia de las relaciones intertextuales generadas por la activa y amplia presencia de Cervantes en un Cunqueiro que desde muy joven siente una especial atracción por el autor del Quijote, según testimonio de F. Fernández del Riego, uno de sus amigos más allegados: "Antre os libros que Cunqueiro releu máis veces - según propia confesión- figuran todo Shakespeare, a Odisea, o Quixote, as "Cartas" de Fray Antonio de Guevara e os Retratos imoxinarios de Walter Pater" ${ }^{8}$. El mismo Cunqueiro le confirmaba también a Carlos Casares la relevancia de la obra cervantina en sus años de aprendizaje:

Por recomendación de aquel home [encargado da Biblioteca Pública de Lugo] tiven que ler todo Palacio Valdés, Pereda e moitas cousas máis. El era moi cervantista, lera moi ben a Cervantes, e por el fixen unha lectura completa do Quijote?.

Esta confesada preferencia de Cunqueiro por determinados escritores tenia que reflejarse necesariamente en el proceso creativo de su propia obra y en la identificación con algunas de las tradiciones literarias que aquellos habían iniciado. Así lo ve en otro esporádico comentario X. L. Franco Grande:

A literatura de Cunqueiro, pra moitos evasiva ou xogo e divertimento, pode ser inscrita nunha liña craramente ibérica que, dende Cervantes aos nosos días - pasando por Eça de Queiroz - afirma o carácter ilusorio de toda realidade ${ }^{10}$.

Todos estos breves y ocasionales apuntes representan, sin embargo, un primer paso en el siempre difícil proceso de cartografiar el complejo escenario literario sobre el que construye Cunqueiro toda su obra, incluso la más estrictamente periodística, y en el

* F. Fernández del Riego, "A vida e a obra dun gran fabulador», Grial, 72, 1981, p. 154.

- Carlos Casares, «Leria con Cunqueirow, Grial, 72, 1981, p. 208.

10 X. L. Franco GrandE, «Introducción a Alvaro Cunqueiro", Grial, 42, 1973, p. 414. 
que la obra cervantina destaca muy especialmente por la abundancia y diversidad de su presencia, a veces con referencias precisas, y otras con alusiones más o menos veladas, aunque, como precisa Elena Quiroga:

Alvaro [Cunqueiro] lanzaba en su obra pequeñas puntadas y alusiones a quienes buscan filiaciones literarias, o a los plagiarios -en quienes creía poco- y lo hacía con finísimo y biendicente humor. [...] Por eso él mismo, con naturalidad, daba la clave de sus lecturas y preferencias".

Las citas, alusiones y paráfrasis de la obra cervantina que Cunqueiro incorpora a la suya indican una clara predilección por el Quijote, con esporádicas alusiones a otros textos del mismo autor ${ }^{12}$. La documentación anterior bastaría para caracterizar al "apasionado cervantino" que fue Alvaro Cunqueiro ${ }^{13}$, pero la presencia de Cervantes en su obra es mucho más extensa y sólida: abarca no sólo una misma concepción del hecho literario, y del proceso narrativo, sino también paralelismos en la proyección de

"Elena Quiroga, Presencia y ausencia de Alvaro Cunqueiro. Madrid, Real Academia Española, 1984, p. 45.

12 Dada la dificultad del acceso a toda la producción periodística y ensayística de Cunqueiro, en la que se encuentran múltiples alusiones y citas de las obras cervantinas, el siguiente inventario de las referencias a determinados textos de Cervantes no pretende ser exhaustivo, aunque sí bastante completo:

Rinconete y Cortadillo. «En una venta del antiguo campo de Alcudia -quizás en aquella misma venta donde don Miguel de Cervantes hizo encontrarse a Rinconete y Cortadillo, que tal alta, parrafeada y graciosa presentación usaronw. Faro de Vigo, 24-IV-1957. "Cervantes es otro espléndido inventor de ventas y tabernas. Basta recordar aquella venta de Alcudia donde se saludan Rinconete y Cortadillo; el encuentro de los pícaros en la venta es una de las páginas más coloreadas y felices de las letras españolasw. Faro de Vigo, 10-X-1963.

Los trabajos de Persiles y Segismunda «Además que el héroe de la novela griega -y desde Rhode sabemos hasta qué punto Ulises y su peregrinación han servido de modelo al protagonista y su pericia, desde entonces a Los trabajos de Persiles y Segismundas. Publicado originalmente en La voz de Galicin serie «Retratos imaginariosw; y editado por C. A. Molina en Viajes imaginarios y reales, Barcelona, Tusquets, 1986, pp. 173-74.

Licenciado Vidriera "Sin contar las ventas de las salidas quijotescas, y la taberna de Génova donde al licenciado Vidriera se le ofrece todo vinow. Faro de Vigo, 10-X-1963. "Cervantes usó la palabra "escabechar" por teñir. Así, en El licenciado Vidriera, dirá "escabechar" por "teñir las canas"". En Fábulas y leyendas de la mar, edición a cargo de Néstor Luján. Barcelona, Tusquets, 1982, p. 267. El artículo "Cuando bebía el licenciado Vidriera" (Faro de Vigo, 13-I-1957) es una deliciosa paráfrasis de la novela ejemplar cervantina.

El coloquio de los perros: «Lémbrense de unha "Novela ejemplar" de Cervantes, na que nos di que "En Sevilla habia obligado de carne" ". A cociña galega Vigo, Galaxia, 1973, p. 24. El texto de Cervantes, perteneciente a El coloquio de los perros, dice precisamente lo contrario: «Y como en Sevilla no hay obligado de la carnew. Novelas Ejemplares II, edición de Harry Sieber. Madrid, Cátedra, 1981, p. 303. Paradójicamente, este tipo de errores, resultado de citas memorísticas, muestra el buen conocimiento que Cunqueiro poseía de la obra cervantina.

13 En un artículo titulado "La Barcelona de Cervantesw incluye Cunqueiro esta velada autoconfesión: «El lector que guste de Barcelona, y sea además apasionado cervantinow, (Faro de Vigo, 2-IV-1964). 
los héroes $y$ en los ejes temáticos que organizan sémicamente ambos mundos literarios.

\section{INTERTEXTUALIDAD NARRATIVA}

El análisis individualizado de cada una de las siete novelas que constituyen el corpus narrativo cunqueiriano ${ }^{14}$ propiamente hablando, arroja un balance especialmente positivo en cuanto a la calidad y variedad de registros cervantinos. Con una ausencia total de citas y escasas referencias, Cunqueiro introduce en casi todas sus novelas códigos cervantinos que generan una riquísima red de relaciones intertextuales ${ }^{15}$.

Merlín y familia, novela por la que el autor sentía una especial predilección, es la única dentro del corpus aquí analizado, que contiene referencias directas a un texto cervantino, concretamente al Quijote. La primera está puesta en boca de Felipe, narrador y antiguo criado de Merlín, que rememora una de las muchas fascinantes situaciones de su niñez:

Pusimos la caja encima de la mesa, y el señor Merlín encendió el quinqué, que a mí mucho me gustaba, que en cada cara tenía sobre el cristal, labradas de latón pintado, escenas de las hazañas de don Quijote: los molinos de viento, los forzados de la galera, los pellejos de vino y el león que iba para el Rey de España (68) ${ }^{16}$.

No debe descartarse la técnica cervantina de la multiplicación de los niveles narrativos que tan sagazmente logra aquí Cunqueiro,

14 ANTONIO ODRIOzOLA, en la que puede considerarse casi definitiva compilación bibliográfica de la obra de Cunqueiro, dedica un apartado a las «Narraciones imaxinadasw, en el que incluye las novelas o narraciones largas: Merlín e familia e outras historias (1955; con una versión en castellano posterior, de 1957); As crónicas do sochantre (1956; y la versión en castellano, en 1959); Las mocedades de Ulises (1960); Si o vello Sinbad volvese ás illas... (1961; con versión en 1962 al castellano); Un hombre que se parecia a Orestes (1968); Vida y fugas de Fanto Fantini della Gherardesca (1972); y finalmente El año del cometa con la batalla de los cuatro reyes (1974). kAlvaro Cunqueiro e unha bi[bli]ografía máis da súa obraw, Grial, 72, 1981, app. 235-260.

is No puede silenciarse lo obvio, que la dinámica intertextual da cuenta de algunos de los momentos más logrados del Quijote. Así lo ve G. GenETTE: «un aspect essentiel de ce récit [Don Quichotte], [...] est évidemment son caractère hypertextuelw, Palimpsestes. La littérature au second degré. Paris, Seuil, 1982, pp. 16465. Pueden consultarse con provecho también DANIEL. P. TESTA, "Don Quijote y la intertextualidad, y FERNANDO DE TORO, «Don Quijote como "desconstrucción" de modelos narrativosw, ambos trabajos publicados en Cervantes. Su obra y su mundo. Actas del Congreso Internacional sobre Cervantes, bajo la dirección de Manuel Criado de Val. Madrid, Edi-6, S.A., 1981.

16 Merlín y familia. Barcelona, Destino, 1973. Todas las notas posteriores refieren a esta edición, indicánduse entre paréntesis el número de página al fin de cada cita. El mismo procedimiento será aplicado a los otros textos narrativos de Cunqueiro. 
como en otros muchos momentos de su narrativa, así como la tensión realidad/ficción.

La complicidad con el mundo literario cervantino vuelve a aparecer en una de las historias que Cunqueiro añade como apéndice al final de la novela; alli se puede leer:

Y con gracioso amor, cuando iba a Lugo o a Gaula y [Merlín] traía algún regalo de mérito para mi ama doña Ginebra, me mandaba vestirme para que se lo llevase yo en bandeja, y me decía, palmeándome en la espalda: -Llévale este galano a doña Dulcinea del Toboso (156).

La otra referencia, localizada en el "Indice onomástico", da entrada a una serie de códigos especialmente relevantes para entender la temprana fascinación que siente Cunqueiro por Cervantes y su mundo; se trata de una mención a Mondoñedo, lugar de nacimiento del escritor gallego, que al ser citado en el prólogo del Quijote, el texto más importante de la hispanidad, no podía ser silenciado por el autor del Merlín y familia, sobre todo si la referencia implicaba también a Fray Antonio de Guevara, otro de sus escritores predilectos ${ }^{17}$ :

Mondoñedo.- Ciudad de Galicia, nombrada en el prólogo del "Quijote» por poner Cervantes cita de famosas cortesanas, que la vida de estas escribiera el-obispo Guevara. [...] En ella nació el señor Cunqueiro [...] que fue quien puso en romance estas historias (206).

La presencia cervantina se incrementa con el comentario final del narrador/autor que al poner "en romance estas historias" registra una fórmula narrativa ya hipercodificada en Cervantes, y

17 Elena Quiroga cita a Cunqueiro aludiendo a la influencia de Guevara en su formación literaria: «No sólo he aprendido mucho y muy buen castellano en él, sino que soy un poco de la naturaleza deformadora y mixtificadora de Guevara. Y tengo conciencia de ellow (20). En el prólogo a El envés (Barcelona, Taber, 1969), Cunqueiro insiste en la misma idea: «Aprendi en él a decir solazado y sabroso, con cierto regodeo de meandros». Pilar Concejo, que documentó "las huellas del obispo de Mondoñedow en El Quijote, señala una serie de rasgos que comparten Guevara y Cervantes, y que definen perfectamente la concepción literaria de Cunqueiro: «Ambos autores [Cervantes y Guevara] abordan la historia como ficción y la ficción como historia, estableciendo una relación directa entre el arte y la vida, la ciencia y la experiencia, lo leido y lo vivido, con el propósito de que el quehacer literario ayude al hombre a comprender la realidad presente y a superarla a través de la nota irónica y humorística» (p. 902). Sobre este mismo aspecto; alude posteriormente: «Los efectos humorísticos [en Guevara y Cervantes] se logran a base de romper el tono solemne del discurso con detalles concretos y vulgarismos, o a base de contrastar el lenguaje culto con notas prosaicas y naturalistas" (p. 905). Como Cunqueiro, kambos autores miran a los tiempos antiguos, a la edad dorada, para por contraste criticar el presente y llamar la atención sobre él» (p. 905). Finalmente, «los dos usan el elemento autobiográfico; reflexionan sobre sí mismos y se convierten en figuras literarias, narrándose a sí mismos y confundiendo en un alarde de modernidad, autor, narrador y protagonista” (p. 907). "Las huellas del obispo de Mondoñedo en El Quijoten, en Cervantes. Su obra y su mundo. Actas del I Congreso Internacional sobre Cervantes. Dirección: Manuel Criado del Val, madrid, Edi-6, S.A., 1981. 
que Cunqueiro empleará más abiertamente en Cuando el viejo Sinbad vuelva a las islas. Rafael Lapesa, en su "contestación" al discurso de recepción de Elena Quiroga, sugiere que:

La misma ironia de Cunqueiro, tan gallego, tiene con frecuencia dejos cervantinos: el anillo mágico donado por Merlín al paje Leonís en una caja de mantecadas de Astorga ¿No está en la misma línea que el corazón de Durantarte sacado por Montesinos con un puñal buido y conservado con sal para que no oliera mal? ${ }^{18}$.

Las crónicas del sochantre ${ }^{19}$ no incluye referencia alguna a la obra cervantina; y sin embargo, teniendo en mente la predisposición cunqueiriana a intertextualizar en su mundo narrativo códigos literarios provenientes del Quijote, no puede desecharse una lectura cervantina de algunos elementos textuales de la novela: la técnica de los manuscritos hallados, por ejemplo, podría interpretarse como un implícito homenaje a Cervantes, aunque su hipercodificación en la historia de la narrativa, y su transformación en hipercódigo dificultaría la demostración de la sombra cervantina; debe quedar constancia, sin embargo, de su uso, y de la peculiar subversión que condiciona su operatividad en ambos autores. Viña Liste reconoce también esta deuda: «el sochantre de Pontivy protagonista de Las crónicas, de cuyas memorias - de acuerdo con el viejo recurso cervantino- dice el novelista haber tomado su relato" ${ }^{20}$.

Cervantes, que incorpora en la segunda parte de su novela "la estraña aventura que le sucedió al valeroso don Quijote con el carro o carreta de Las Cortes de la Muerte" "2, podría ser también fuente de inspiración en Las crónicas para los acontecimientos que rodean la ambigua carroza que conduce a la hueste de los difuntos a Comfront, para representar la «Pasión y muerte de los leales amadores Romeo y Julieta en la hermosa ciudad de Verona de Italia» (131). Cristina de la Torre ve también la huella cervantina en el siguiente fragmento ${ }^{22}$ :

Decía yo [habla el médico Sabat] que los ensayos de los venenos no me dejaban ni dormir, y por hacerme conocer como inglés de tan alta sangre y mantener conmigo tantas secretas conversaciones políticas, llegué a darme crédito a mi mismo, y ya pensaba en salir para Inglaterra (84).

Vida y fugas de Fanto Fantini ${ }^{23}$, novela ambientada y anclada temporalmente en un mundo tan querido de Cervantes, el de la

18 Elena QuiRoga, p. 155.

19 Barcelona, Destino, 2." ed., 1966.

20 J. M. VIÑA LISTE, "Para la estilística de la narrativa de Cunqueiro", en Homenaxe a Alvaro Cunqueiro. Santiago de Compostela, Univ. de Santiago de Compostela, 1982, p. 24.

"Parte Segunda, capítulo 11.

22 La narrativa de Alvaro Cunqueiro, Madrid, Pliegos, 1988, p. 74.

23 Barcelona, Destino, 1972. 
Italia renacentista, permite también la identificación de códigos cervantinos, aunque siempre matizados por la ambigüedad y el sello personal que Cunqueiro imprime a toda su escritura. Este intercala un relato "Las gulas del clérigo que leía etrusco", que contiene elementos de fácil identificación en el Quijote, he aquí los fragmentos cuyo calco cervantino es fácilmente perceptible:

Botelus se subió a una banqueta, [y] se apoyó sobre dos odres de tinto que estaban de pie. [...] A las voces de Botelus habían acudido el mesonero, su hija, dos arrieros cordobeses, y un lego franciscano, que corría a la limosna. [...] Botelus se reía, se contemplaba las rayas de sus manos ambas, se daba golpes en el bonete y en el pecho, tiró media onza de oro al posadero como pago de los odres de vino tinto cuyos piezgos desató, y comenzaron a verter $(132-33)$.

Cunqueiro selecciona cuidadosamente, sin transgredir los límites de lo irreconocible, pero al mismo tiempo evitando el plagio redundante, una serie de registros que el lector, familiarizado con la obra cervantina, puede controlar intertextualmente; en este caso, el texto que funciona como horizonte de recepción es el famoso capítulo 35 de la Primera parte del Quijote.

Como Cervantes, Cunqueiro en Vida y fugas de Fanto recurre a la autorreferencialidad metafictiva incorporando en la diégesis de la segunda parte de la novela referencias literarias al personaje central, Fanto, que como el mismo don Quijote, se ve proyectado como héroe literario:

En su discurso ante el Senado de la Serenísima, «Liofante* afirma que Fanto abandonó la isla con la ayuda de siete delfines, pero los comentaristas creen que este pasaje corresponde a la fuga de Tamnos a Chios, episodio conocido con el nombre de «Amores de Safo con el delfín de Italia", que ahora se edita con otras novelas griegas, y en la que el propio Fanto es descrito como un gran señor de Italia al que la maga Cósima convierte en delfín para que nunca más vuelva a tierra a amar a Safo, a la que Cósima ama. Safo permanece fiel al príncipe-delfín. Como se ve, se trata de un arreglo alejandrino posterior (106).

Remo, el perro fiel de Fanto, muestra unos rasgos que lo emparentan con la tradición de los relatos lucianescos tan conocidos de Cervantes como demuestra en El coloquio de los perros, novela ejemplar que Cunqueiro cita en alguna ocasión ${ }^{24}$.

La última novela del escritor gallego, El año del cometa con la batalla de los cuatro reyes ${ }^{25}$, sigue demostrando la persistente vocación cervantista del autor. Como en las novelas precedentes, apenas pueden señalarse situaciones o calcos de una proximidad excesiva. Cunqueiro maneja la dinámica de la intertextualidad

24 Cfr. nota 12.

25 Barcelona, Destino, 1974. 
con una excepcional sagacidad, instalándose en el límite de la imitación y de la subversión, cuyo balance sería la parodia ${ }^{26}$.

Paulos, personaje central de la novela, comparte muchos rasgos con don Quijote; las similitudes, a veces de tipo estructural (como la configuración de la personalidad del héroe), están reforzadas por detalles diegéticos que funcionan como pistas estratégicas especialmente diseñadas para jugar con el lector. En el caso de $E l$ año del cometa es posible detectar varias unidades narrativas que refieren al lector a un horizonte de espectativas constituido por la obra cervantina:

El caballo de Paulos, al que se refiere en la novela como "rocín» (167), es descrito en términos que obligan al lector a identificarlo con Rocinante. La presencia de un ama, y de su sobrina (aunque en la novela cervantina se trata de la sobrina de don Quijote) no deja de ser significativa como un código actancial en una novela que, como las otras del mismo autor, mantiene estrechas relaciones intertextuales con la obra de Cervantes, sobre todo con su concepción de la novela, y del hecho literario en general. Como don Quijote, Paulos se siente impelido por su imaginación a salir a un nuevo espacio en busca de aventuras, y se dirige a la Selva, para encontrarse con sus modelos literarios. El siguiente texto viene a confirmar los datos anteriores importantes: "Paulos, para el viaje, se había vestido medio de soldado romano, medio de Lanzarote del Lago, según grabados de libros» (167).

Dada la confesada atracción de Cervantes y Cunqueiro por la tradición literaria medieval árabe, no debiera extrañar que la voz cervantina se haga todavía más visible en Cuando el viejo Simbad vuelva a las islas ${ }^{27}$. Una lectura rápida de esta novela permite identificar los siguientes códigos provenientes del Quijote:

La voz narrativa esta personificada en un: "Yo, Al Faris Ibn Iaqim al Galizí, que pone en latino castellano estas memorias" (18). $Y$ en el recuento final de los personajes de la novela, que Cunqueiro suele añadir al final de sus novelas, incorpora la imagen de: "Al Faris Ibn Iaqim al Galizi.- Nombre arábigo de Alvaro Cunqueiro, hijo de Joaquín y de nación gallega, y autor de esta historia de Simbad Marino. Se hace pasar en el texto por traductor de arábigo al latino en la imperial ciudad de Toledo, en los días de la famosa escuela alfonsín (155). Este narrador, como en el Quijote, también estudia en "cartapacios" en la ciudad de Toledo: "Yo, Al Faris Ibn Iaqim al Galizí, [...] hacía examen en Toledo de traductor, y pasaba por cartapacio lengua latino-romana..." (109).

26 Conviene precisar, como afirma Herman Meyer en The Poetics of Quotation in the European Novel (Princeton, N.J., Princeton Univ. Press, 1968), que "parody by no means requires a hostile attitude toward the object of parody and that it is misleading to conclude automatically that such an attitude exists" (p. 69).

27 Barcelona, Destino, 1962. 
Los mecanismos de proyección literaria del héroe de Cunqueiro siguen unos parámetros muy semejantes a los que configuran la imagen literaria de don Quijote, impelidos ambos por la necesidad de un réconocimiento público. He aquí los textos cunqueirianos que permiten vislumbrar las obsesiones quijotescas de Simbad:

Simbad le anunció quién era él, y quedó algo cortado cuando el otro le respondió que nunca oyera hablar de aquella señoría, y eso que podía decirse que lo suyo propio era vivir en los muelles del mundo entero. Se habían acercado marinero y tratantes, y bien vieron que Simbad iró, colorado, de no verse famoso. (36-37)

$\mathrm{Y}$ guardando el mondadientes dijo quién era, y por como levantaron todos las cabezas y miraron. para él se complació en ver que era conocido su nombre. (114)

Yo, señor lancero real, soy el que fue piloto mayor del Califa de Bagdad, conocido por Simbad el Marino, y tú eres muy joven y de tierra adentro para que mi nombre famoso te diga algo. (119)

Bajó Simbad más entristecido que irritado, y pensando si tendría en Basora algún conocido, o en ir al caid, que quizá tuviese memoria leída u oída de él. $(120-121)^{28}$

De todos los héroes de Cunqueiro, Simbad es el que se mueve ya desde el principio impelido por una imaginación imposible, que lo convierte en un alter ego del héroe de Cervantes. En esta misma novela, estructurada sobre un eje de oposiciones actancial representado por el visionario Simbad y su escéptico criado Sari, los momentos de tensión entre las fugas imaginarias del héroe y la actitud incrédula de su joven ayudante apoyan con mayor intensidad, si cabe, la lectura cervantina de Cuando el viejo Simbad, como sugiere el siguiente fragmento:

La más de la gente es burlona sin caridad. Pero nuestro Sinbad echó una mirada por encima del mundo [...].

- Más de siete hijos de puta aún estarán durmiendo! - comentó Sari, quien anduviera aquellos días muy abromado por los graciosos de la villa, que le preguntaban si ya regresara de las Molucas. (111-12)

El paralelismo sugerido entre don Quijote y Simbad, y los rasgos comunes que definen la actitud incierta y ambigua de sus respectivos criados, ayudan al lector a identificar la novela de Cervantes como uno de los horizontes de espectativa que configuran activamente el mundo narrativo de esta novela de Cunqueiro. Viña Liste ve en la descripción de Simbad imaginando una explicación para el "ćamisón lleno de zurcidos y remiendos" ecos del héroe cervantino:

26 Subrayados mios. 
Es adivinable en el pasaje aducido el guiño humorístico y simpatético de la referencia implicita cervantina, con don Quijote al fondo afligido por sus calzas descosidas y remendadas, recomponiéndolas a hurtadillas ${ }^{29}$.

Cristina de la Torre identifica en esta misma novela otro fragmento, reminiscente del de la celada quijotesca:

Guarda cuatro cajas herradas llenas de variedades, pero nunca las abre, y digo yo que será para no desencantarse a sí mismo hallándolas vacías, o si lo que guardan son espejos rotos, conchas y trapos viejos. (53-54)

Otro fragmento de obvias resonancias cervantinas es el que narra la salida de Simbad, acompañado de sus dos ayudantes, hacia Basora; los calcos son inmediatamente perceptibles:

Y los tres se pusieron a caminar por aquellos llanos vecinos del desierto [...]. Los perros de los pastores los saludaron con ladridos que a Simbad se le antojaban alegres. (112)

El siguiente texto, perteneciente al momento en que Simbad llega a las afueras de Basora, representa otro momento clave en esta sistemática intertextualización cervantina dentro de la narrativa de Cunqueiro, concretamente el capítulo II.9, en el que se narra la llegada de don Quijote y Sancho al Toboso en busca de Dulcinea:

Falta media hora para el cañón serotino, y si apuramos quizá llegáramos antes de que cerrasen todas las puertas, pero mejor es que durmamos hoy fuera, en un bosquecillo de higueras que tenga fuente, y mañana temprano [...] entremos por la Puerta Mayor y la Calle Mediana y nos acercamos a los astilleros, sin prisa, como ricos confiados. (117) dice:

El texto cervantino intertextualizado en el fragmento anterior

- Señor, ya se viene a más andar el día y no será acertado dejar que nos halle el sol en la calle; mejor será que salgamos fuera de la ciudad, y que vuestra merced se embosque en alguna floresta de aquí cerca, y yo volveré de día ${ }^{30}$.

Como se insinúa más arriba, Cunqueiro desecha obviamente la tentación del plagio, sobre todo cuando se trata de un texto tan canónico como el Quijote. El escritor gallego prefiere una modalidad de absorción mucho más difusa y al mismo tiempo más rica: incorpora un código determinado y luego lo resemantiza hasta transformarlo en elemento activo dentro de su propio espacio literario. El fragmento anterior es un ejemplo paradigmático de

29 Viña Liste, p. 13. Elena Quiroga, por su parte, vincula este mismo pasaje con el «tractado terceron del Lazarillo de Tormes (op. cit., p. 86).

3o El Ingenioso Hidalgo Don Quijote de la Mancha, edición de Luis Andrés Murillo, Madrid, Castalia, 1973, vol. 2, p. 103. 
esta cuidadosa técnica manipuladora, que reconfigura los distintos códigos (narrativos, semánticos, sintácticos, léxicos, etc.) pertenecientes al texto intertextualizado.

El final de la novela, con un Simbad que vuelve a casa ciego, y abatido por el fracaso de sus propios sueños, subido a una burra, le ofrece al lector otra clave cervantina. Como en el Quijote, el aspecto performativo de la técnica narrativa ocupa un lugar especialmente destacado para entender la configuración textual de la novela: el héroe de Cunqueiro, al proyectarse como Simbad el Marino (personaje literario perteneciente a una determinada tradición cultural), impone una lectura fictiva de la diégesis, lectura reforzada por la intencionalidad paródica que preside la configuración heroica del viejo Sinbad.

Esta lectura cervantina del héroe de Las mil y una noches que Cunqueiro articula en su novela, seria posteriormente retomada por Lezama Lima, quien en Paradiso sugiere una interpretación de la figura de don Quijote, relacionándolo con Sinbad:

En mi opinión, Don Quijote es un Simbad que al carecer dè circunstancia mágica del ave rock que lo transportaba, se vuelve grotesco. Como Simbad hace salidas, el ave rock puede transportar un elefante, pero si tiene que levantar un esqueleto y dejarlo caer sobre una peladura de roca, el resultado es un grotesco sin movilidad [...]. El ave rock levita a Simbad y lo lleva a una llanura de polvo, pero. Sancho y su rucio gravitan sobre Don Quijote y lo siguen en sus magulladuras, pruebas de su caída icárica ${ }^{31}$.

En las otras dos novelas que completan el ciclo cunqueiriano, Las mocedades de Ulises ${ }^{32}$ y Un hombre que se parecia a Orestes ${ }^{33}$, no son detectables tan directamente como en los textos narrativos anteriores códigos literarios cervantinos. Sin embargo, estas dos novelas ejemplifican de forma paradigmática la concepción de lo literario que Cunqueiro puso en práctica desde sus primeros relatos, y que tan cerca está de la imaginación literaria cervantina. El Ulises de Cunqueiro, como don Quijote, juega con las identidades de los famosos héroes de las novelas de caballerías, como le confiesa irónicamente a la paralítica Elena: "-Me llamo Amadís, don Amadís de Gaula, y mis armas son la pluma negra del ala del cuervo en campo de sínoplew (159). Este mismo rasgo es detectable en Un hombre que se parecia a Orestes, como muestra el siguiente fragmento:

Y viendo un fresno joven en el lindero del bosque, apeándose del caballo tiró de la navaja y cortó la más esbelta rama [...], y con un cordón del jubón ató su puñal y su pañuelo verde [...]. Y ya dueño de lanza con

31 Paradiso, Madrid, Fundamentos, 1976, p. 256.

32 Barcelona, Destino, 2." edición, 1970.

33 Barcelona, Destino, 1969. 
bandolera, trotó por aquellos claros, poniendo la mano izquierda de visera por ver si aparecía a lo lejos la figura de una aventura, y deteniéndose pensativo en las encrucijadas, como los héroes que pintan los libros de caballerías (127).

Un texto que conserva el intenso tono paródico cervantino, como muchos otros fragmentos de estas dos últimas novelas en las que sus personajes principales se proyectan como héroes de las novelas de caballerías. Que Cunqueiro, en este momento de su novela, tiene en mente el Quijote como horizonte de referencia lo atestiguan no sólo determinados códigos de la cita anterior, sino también la referencia a unos "molinos" ("Egisto temió ser visto desde los molinos"), y a una "venta" (128).

\section{JUEGOS DE ERUDICIÓN PERIODÍSTICA}

Cunqueiro es uno de esos escritores que desconocen límites discursivos y genéricos en el proceso creativo de la palabra. Las innumerables series de artículos periodísticos, aparecidos en diarios y revistas, permiten completar la imagen de este escritor fascinado con su oficio de logoteta, es decir, fundador o refundidor de la palabra ${ }^{34}$. Si su producción narrativa apenas ha sido objeto de estudio, la situación con respecto a la colección de artículos todavía está en una fase inicial de recopilación.

Las antologías disponibles permiten corroborar la fascinación cunqueiriana por la obra de Cervantes mostrada en sus novelas. Aquí, sin embargo, los juegos intertextuales están mucho más diversificados, y sujetos a propósitos distintos. A diferencia del corpus narrativo, en el que Cunqueiro se ciñe al mundo del Quijote, en los artículos aparecen referencias a otros textos cervantinos, aunque la gran novela cervantina sigue acaparando la fascinante erudición imaginativa del autor gallego.

Dada la mútiple diversidad temática de los artículos y el carácter impredicible de los juegos de erudición cunqueirianos, no resulta fácil organizar de una forma sistemática las citas cervantinas, y menos todavía penetrar en los mecanismos discursivos que Cunqueiro pone en funcionamiento, de cualquier forma, y como se trata de poner de relieve la presencia de Cervantes en su corpus periodístico, podría funcionar, aunque con carácter provisional, la siguiente clasificación:

\section{Cervantes como autoridad}

En muchas ocasiones, Cunquerio cita al autor del Quijote para legitimar su propia visión o interpretación de la realidad comentada

34 Es R. BARTHES quien sugiere este calificativo, que él aplica a Sade, Fourier y Loyola, en Sade/Fourier/Loyola, Paris, Seuil, 1971. 
en el artículo correspondiente: «Pero según las historias de amor, y es $^{+}$o lo sabia muy bien Cervantes, se sacan del enamorado amante que uno es" ${ }^{35}$; la siguiente es una cita cervantina que Cunqueiro utilizó en varios de sus artículos: "Pero la verdad es lo que dijo Cervantes que "nadie sabe nada del alma de nadie"" ${ }^{36}$. Otras veces, Cunquerio lo utiliza como código cultural universal: «Hablo del ser humano, desde Nefertiti y Helena a Platón y al Discóbolo, desde Esquilo [...] a Cervantes y Shakespeare" "37; o como fuente léxica: «De "duerna" a "dorna" viene "dornajo". [...] También aparece en el Quijote y en Covarrubias" ${ }^{38}$.

\section{Don Quijote}

El personaje cervantino es, como ya queda dicho, referencia obligada para Cunqueiro; y, un poco como Unamuno, le da vida propia proyectándolo más allá de los límites del mundo cervantino, como apoyo de su ludismo incontrolado. Los siguientes textos, seleccionados de los artículos que C. A. Molina recopiló bajo el ya citado título de Viajes imaginarios y reales, dan una idea bastante precisa de las manipulaciones intertextuales a que somete Cunqueiro la figura de don Quijote: "Y desde don Galaz hasta los Doce Pares y el señor don Quijote, pudo llevar [Maria] a toda la cristiana y pura caballería andante por escolta" (96). A veces, como el siguiente comentario, las notas rezuman ironía y humor: «Fueron muy escasos los andantes caballeros que no eran analfabetos: [...] don Quijote de la Mancha, éste, quizás, el más letrado de todos" (186-187). Con la misma distancia irónica hay que leer este otro manifiesto:

Como es sabido, para don Quijote no había oficio más conveniente en el Universo mundo, más alto, sacrificado y necesario que el de los caballeros andantes, siempre en los caminos, desfaciendo entuertos, protegiendo huérfanos y viudas, y estableciendo la paz y la justicia. Con sólo cien caballeros andantes en el ejercicio bastaría para que se pudiese decir de aquel tiempo que lo era de oro, dorado (191).

La edad de oro, o el paraíso perdido, su otra cara, es uno de los temas recurrentes en toda la obra de Cunqueiro. Tal es así que

\footnotetext{
" De la serie El mundo y la sombra, reproducido en Viajes imaginarios y realeş. Barcelona, Tusquets, 1986, p. 85.

" "Viudas en peregrinación», Sábado Gráfico, 30-4-1980. En otro artículo, "La sirena de Génovaw, recopilado por Néstor Luján en Fábulas y leyendas de la mar. Barcelona, Tusquets, 1982, puede leerse una variante de la misma cita: «Mayores locuras se vieron, y ya dijo Don Quijote que nadie sabe nada del alma de nadiew (p. 197).

" "Las señales de los siglos", reproducido en Viajes imaginarios y reales. Barcelona, Tusquets, 1986, p. 267.

* Fábulas y leyendas de la mar, p. 132.
} 
bien podría estar clasificado entre los ejes de organización sémica de toda su producción literaria y periodística.

A veces Cunqueiro, recurriendo a ese prosaico tono coloquial en que envuelve todos sus juegos de erudición, incide en aspectos de la obra cervantina que ha sido objeto de investigación; refiriéndose, por ejemplo, a la climatología, llama la atención sobre la escasez de lluvia en el Quijote.

Y si don Quijote, hablando de la vida sacrificada de los andantes, alude a su caminar bajo el ardiente sol o las grandes lluvias, la verdad es que en los libros en que se cuentan las hazañas de los andantes nunca llueve. En el Quijote mismo tampoco llueve, que yo recuerde. (192) ${ }^{39}$.

La imagen de don Quijote aventurándose por uel antiguo y conocido campo de Montiel" es objeto de repetidas paráfrasis por parte de Cunqueiro en sus artículos, como prueba la siguiente selección de textos:

Y yo creo que tal los iba imaginando [los caminos de aventura] el señor don Quijote cuando, a la del alba sería, cruzaba el antiguo y conocido campo de Montiel ${ }^{4}$.

Amanecer con ellos [gente antigua, heroica y lacónica] en mayo, es como amanecer con Alonso Quijano por el antiguo y conocido campo de Montiel cantando - como dijo Don Quijote que le gustaba hacer- octavas de Ariosto ${ }^{4}$.

A veces es un mínimo detalle el que utiliza Cunqueiro como vehículo de transmisión del mundo cervantino: "La liebre que Alonso Quijano comería, cazada en el antiguo y conocido campo de Montiel por su galgo corredor" ${ }^{42}$; que incorpora un elemento perteneciente al famoso párrafo introductorio del Quijote: «En un lugar de la Mancha, de cuyo nombre no quiero acordarme, no ha mucho que vivía un hidalgo de los de lanza en astillero, adarga antigua, rocín flaco y galgo corredor" ${ }^{43}$. Esta manipulación del texto cervantino es especialmente sugerente en cuanto a las fórmulas de intertextualización empleadas por Cunqueiro, que proyecta al héroe de Cervantes y su diégesis correspondiente más allá de los límites definidos por el texto original. Con estos momentos iniciales de la novela cervantina, jugará también en otra ocasión: «El verdugo [...] vivió de señor el resto de su vida, co-

${ }^{39}$ Este mismo aspecto ha sido estudiado por J. L. MURILLo, "The Summer of Myth: Don Quijote de la Mancha and Amadis de Gaulon, Philological Quarterly, 51, 1972, pp. 145-57.

4o Viajes imaginarios, p. 231.

"Viajes imaginarios, p. 243.

42 Viaje por los montes y chimeneas de Galicia. Caza y cocina gallegas. Madrid, Espasa-Calpe, 1978, p. 210. Subrayado mío.

${ }^{4}$ El Ingenioso Hidalgo Don Quijote de la Mancha, p. 69. 
miendo a diario olla de vaca y de carnero, y los domingos, como Alonso Quijano, un palomino de añadidura" ${ }^{44}$.

La atracción que ejerce la literatura de caballerías sobre Cunqueiro, como demuestra su producción narrativa, está perfectamente definida también en las constantes referencias aparecidas en sus artículos periodísticos ${ }^{45}$, en las que frecuentemente don Quijote actúa de catalizador, como confirman las siguientes citas:

Y supongo que el elegir a San Francisco para tal oficio sería por aquella veleidad de andante caballero que tuvo en la flor de su mocedad, y que le hizo salir jinete al campo lanza en ristre, alterado su ánimo soñador con la flor de los romances carolingios y las leyendas artúricas, como salió vuelto el seso con la lectura de libros de caballerías, a la del alba sería, nuestro don Quijote de la Mancha *.

El caballero [cruzado de Chaucer] nos lleva a imaginaciones de Don Quijote: "pese a su bravura era discreto, y en razones, blando y medido como una doncella" 4 .

El caballero que no sabe huir! No podría encontrar nadie, ni don Quijote de la Mancha, mejor definición del andante caballero ${ }^{* 8}$.

Otro personaje cervantino por el que Cunqueiro siente una especial atracción es el Caballero del Verde Gabán. Incorporado en uno de sus poemas ${ }^{49}$, adquiere una mayor presencia en los

4 "La insula de Iazid al-Srirw, Faro de Vigo, 16-11-63. He aquí el texto cervantino correspondiente: «Una olla de algo más vaca que carnero, salpicón las más noches, duelos y quebrantos los más sábados, lentejas los viernes, algún palomino de añadidura los domingos, consumian las tres partes de su hacienda» (op. cit., pp 69. 70).

45 En «La toma de Jerusalén", artículo publicado en Faro de Vigo (28-9-58), Cunquiro confiesa: «Ando estos días metido en lecturas y relecturas de libros de caballerías». Un año más tarde, el escritor mindoniense seguía "repasando notas de lecturas de libros de caballerias"; Faro de Vigo, 24-9-59. Este decidido gusto por las fabulaciones del mundo artúrico llevan a Cunqueiro a declarar que: «Para la historia de la filosofía - que o es la historia de los apetitos, sueños, nostalgias, inquisiciones y fantasmas del hombre o no es nada, tanto me ayuda Platón como el Amadís de Gaula, tanto Gargantúa y Pantagruel como Hegelw; Faro de Vigo, 10 5-53.

4. «San Froilán a la jineta», Faro de Vigo, 5-10-58.

4 «En la posada del Tabardo», Faro de Vigo, 19-6-51.

48 "Los guardianes de la cruz", Faro de Vigo, 2-6-64.

4 Entre los poemas neotrovadorescos de Dona do corpo delgado (1950) figura la siguiente composición, la IV de las "Cantigas do amor cortésw:

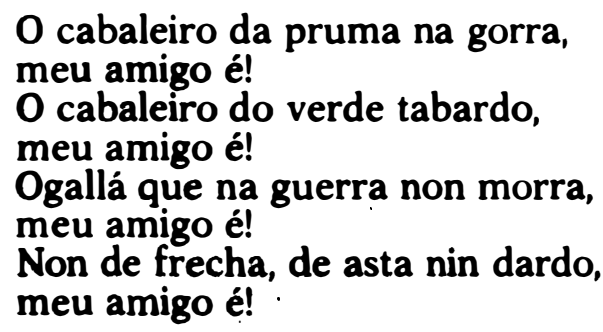

Obra en galego completa. Poesía. Teatro. Vigo, Galaxia, 1980, p. 126. 
trabajos periodísticos. En Viaje por los montes y chimeneas de Galicia. Caza y cocina gallegas, Cunqueiro incluye un "Discurso preliminar; laude a Diana, escolios a Baco y epístola a los cocineros y cocineras", firmado por "El Caballero del Verde Gabán». El texto, que E. Quiroga califica de "delicioso, con una larga entrada en el castellano del Siglo de Oro, implícito homenajen ${ }^{50}$, es una muestra más de la pericia retórica y fabuladora de Cunqueiro, que asimila con una facilidad realmente envidiable cualquier modalidad discursiva literaria, estableciendo los parámetros de una dinámica intertextual organizada sobre los principios de la autoridad canónica del texto incorporado y de su subversión. Este mismo personaje cervantino es aludido en uno de los artículos periodísticos de la serie El envés: "Yo comparto la curiosidad de las invenciones con el hijo del Caballero del Verde Gabán, aunque lo burlase el señor don Quijote» ${ }^{51}$. En relación con esta enigmática figura, una de las mejor trabajadas por Cervantes, hay que señalar un rasgo que define a casi todos los héroes de Cunqueiro: sus vistosas y llamativas indumentarias, en las que predominan los colores verde y rojo ${ }^{52}$.

so Quiroga, p. 57.

"1 "Del Siam lejano y de Semiramis», Faro de Vigo, 11-6-69.

\$2 La siguiente selección, tomada de la producción narrativa de Cunqueiro, confirma la peculiaridad colorista aludida:

Merlin y familia «Brincaron fuera del mimbre sis hombrecillos de menos de cuarta leonesa, vestidos de verde y colorado» (91). «El señor vizconde de Ribeirinha [...] del bolsillo del chaleco verde, verde como los ojos de Carla cantora, sacó la navajita" (142). "Y Cobillón iba de levita verde y bastoncillo de plata" (151).

Las crónicas del sochantre. «Un jorobeta que parecía tener azogue en el cuerpo, solemne bigote, casaca verde» (133). "Es un mozo joven, con casco de plata y abrigo rojo. En el brazo derecho trae una cintaw (141).

Las mocedades de Ulises: "Era pariente de los que son príncipes entre los samios: alto, flaco, siempre vestido de verde" (39). «Buscaria un héroe de lento paso, mozo y fatigado, vestido de vivos colores..." (111). «Ese forastero, que sube del muelle a la posada de la ciudad, abanicándose con su sombrero verde" (130). "[Que] llevase puesto un vestido de cazador que me habian comprado en Cork, con jubón con capucha, todo verde" (148). "[Ulises] saludó con la montera nueva, en la que brillaban verdes abalorios" (155).

Cuando el viejo Sinbad vuelva a las islas. «Sinbad se ponía una camisa blanca de maestresala y un gorro verdew (55). "Te sentaba muy bien la camisa verdew (141).

Un hombre que se parecia a Orestes: "Ya le tenia buscado el difunto un marido, un gentilhombre campesino, que llegó a pedir la mano saludando desde lejos con un sombrero verdew (156).

Vida y fugas de Fanto Fantini "Y el cavaliere de hábito de San Juan y Fanto a la florentina, de verde y oro, fueron a la visita» (24). «Apareció Fanto Fantini [...] vestido de verdew (72).

El año del cometa «El hombre del sombrero verde se había sentado en el bancow (25). Todo el segundo prólogo de la novela gira en torno a este objeto, hasta el punto de transformarse en el eje semántico de la secuencia narrativa. 


\section{CONCLUSIÓN}

Este recuento de la presencia cervantina en la producción narrativa y periodística de Cunqueiro, sin pretender la exhaustividad, demuestra cuantitativa y cualitativamente que el mundo literario de Cervantes constituye uno de sus horizontes de reflexión y proyección, al lado de Shakespeare, Dante, Villon, Guevara, Stendhal, Yeats y Lord Dunsany, entre otros. Como pocos escritores de su generación, Cunqueiro reflexiona creativamente sobre la historia literaria europea, homologando al modo cervantino una poética de la lectura con la de la escritura. Su obra prueba que la evolución de los sistemas literarios se mueve mediante el inacabable proceso de producción, reproducción y subversión de los sistemas de codificación literaria. A este proyecto Cervantes aporta no sólo su propio mundo literario, múltiples veces textualizado en la obra cunqueiriana, sino también, y sobre todo, una concepción del hecho literario que Cunqueiro cultivaría a lo largo de toda su vida. 